\title{
CHLOROPHYLL CONTENT AND ITS RELATION TO PRODUCTIVITY OF CROPS AND WEEDS IN A TROPICAL AGROECOSYSTEM AT GUJAR LAKE MARGIN, INDIA
}

\author{
Mayank Singh and Mahendra Pratap Singh* \\ Department of Botany \\ T.D.P.G. College, Jaunpur-222002, U.P., India \\ *Email: mahendraprtapsinghtdpg@gmail.com
}

\begin{abstract}
The paper deals with evaluation of magnitude of changes in chlorophyll concentration, chlorophyll density and relationship of chlorophyll density with net primary productivity of mixed winter crop (wheat and mustard) community at Gujar lake margin in the district Jaunpur (U.P.). The chlorophyll concentration of each component of crops, dominant weed Cynodon dactylon (Linn.) Pers. and 'other weeds' have shown increasing trend in the beginning and reached their peak values at the same time (75-90 days). Thereafter, chlorophyll concentration have declined sharply. Maximum chlorophyll density value of total crop (wheat and mustard) was $2015.77 \mathrm{mg} \mathrm{m}^{-2}$ and for total weeds was 810.08 $\mathrm{mg} \mathrm{m} \mathrm{m}^{-2}$, both at the age of 90 days of crop. There was a significant positive correlation between productivity and chlorophyll density of total crop $(r=0.903, p=0.002)$ and total weeds $(\mathrm{r}=0.580, \mathrm{p}=0.131)$.
\end{abstract}

Key words: Chlorophyll, lake margin, agro-ecosystem, Net primary productivity, mixed crop.

\section{INTRODUCTION}

The chlorophyll of plant community is an important parameter for characterizing photosynthetic productivity of an ecosystem. Newbould (1967) and Milner and Hughes (1968) indicated the importance of chlorophyll concentration estimation as a quantitative measure of the photosynthetic system in all International Biological Programme projects. The community chlorophyll concentration per unit area according to Odum (1971) is an example of 'community homeostasis'. Leaf chlorophyll is a good indicator of photosynthesis activity (Chaoyang et al. 2008). Several ecological processes, particularly phytomass and production are influenced by the amount of chlorophyll density per unit area (Misra and Mall 1975, Ambasht et al. 1983, Gitelson et al. 2006). But this kind of study of magnitude of the changes in chlorophyll concentrations in terms of both dry weight of plant material and ground area of margin of 'Gujar Tal' with specific reference to crop-weed contribution in different ages of mixed winter crop is a few in tropical climate. 


\section{MATERIAL AND METHODS}

Study site: The present study was conducted from November, 2008 to first fortnight of March, 2009 in the north western part, $28 \mathrm{~km}$ from Jaunpur city and $1.5 \mathrm{~km}$ away in the west of Khetasarai town area at lake margin of 'Gujar Tal' $\left(24^{\circ} 6^{\prime}-25^{\circ} 5^{\prime} \mathrm{N}\right.$ and $80-82^{\circ} \mathrm{E}$ longitude) in the tropical semi-arid region in eastern U.P. The study site was $50-200 \mathrm{~m}$ with slight sloppy topography about $7-12^{\circ}$. Major part of the study site was inundated with water after first fortnight of July to September during the year of the study. The texture of soil was more or less sandy clay loam in first depth $(0-10 \mathrm{~cm})$ and clay loam in last two depths $(10-20 \mathrm{~cm})$. The soil $\mathrm{pH}$ of the study site ranged in the alkaline side between 7.0-8.0.

The climate is typically monsoonic with three different seasons viz. summer, rainy and winter. The total rainfall from April, 2008 to March, 2009 was $1346.8 \mathrm{~mm}$ out of which about $1295.4 \mathrm{~mm}$ was during rainy season and it was only $2 \mathrm{~mm}$ during winter crop period including $49.4 \mathrm{~mm}$ the casual summer rain.

Crop operation: After the flood-water had receded, intensive ploughing was done at the study site in the second week of November, 2008. In the middle of November wheat (Triticum aestivum, Linn. variety Malvi, 234) and mustard (Brassica compestris Linn. variety Varuna, 59) were sown together by applying urea $50 \mathrm{~kg} \mathrm{ha}^{-1}$ and di ammonium phosphate $50 \mathrm{~kg} \mathrm{ha}{ }^{-1}$ fertilizers (equivalent to $32 \mathrm{~kg}$ nitrogen and $32 \mathrm{~kg}$ phosphorus) at the sowing time. Irrigation of crop was done with lake water whenever required during winter cropping.

Sampling, experimental observation and calculation: On the basis of Importance Value Index (IVI), C. dactylon (Linn.) Pers. the most dominant weed was studied separately and remaining weeds were put together as 'other weeds'. Crops IVI were quite high for $T$. aestivum and B. compestris, which were selectively cultivated.

Fresh samples of wheat, mustard, dominant weed and 'other weeds' were collected separately from the study site in proportion to their density and brought to the laboratory in ice cans containing ice to avoid the breakdown of pigment. Plant components were separated and divided into four subsamples, one to obtain a constant dry weight in an oven at $80^{\circ}$ for $48 \mathrm{~h}$ and other three for chlorophyll determination. $0.25 \mathrm{~g}$ of the plant sample was placed in $15 \mathrm{ml}$ of $80 \%$ acetone in stoppered conical flask, kept overnight in a refrigerator at $4{ }^{\circ} \mathrm{C}$ and later homogenized and centrifuged at $3000 \mathrm{rpm}$ for $15 \mathrm{~min}$ within $80 \%$ acetone. Optical density of the extracts was measured in spectrocolorimeter at 633 and $645 \mathrm{~nm}$ wavelengths for chlorophyll determination. Plant samples were taken for known area of lands (quadrats) and chlorophyll content for $\mathrm{m}^{-2}$ was calculated.

The amount of chlorophyll $\mathrm{a}$ and $\mathrm{b}$ were calculated by using formulae given by Machlachlan and Zalik (1963):

Chlorophyll a $\left(\mathrm{mg} \mathrm{g}^{-1}\right.$ dry weight $)=\frac{12.3 \mathrm{D}_{663}-0.86 \mathrm{D}_{645}}{\mathrm{~d} \times 1000 \times \mathrm{W}} \times \mathrm{V}$
Chlorophyll b $\left(\mathrm{mg} \mathrm{g}^{-1}\right.$ dry weight $)=\frac{19.3 \mathrm{D}_{645}-3.6 \mathrm{D}_{663}}{\mathrm{~d} \times 1000 \times \mathrm{W}} \times \mathrm{V}$

Where, $\mathrm{V}$ is volume of chlorophyll extract in $\mathrm{ml}, \mathrm{d}$ is length of light in $\mathrm{cm}$, and $\mathrm{W}$ is dry weight of plant samples taken in $\mathrm{g}$.

The total chlorophyll value was obtained by adding chlorophyll a and $b$. The density of chlorophyll was then calculated per unit area of ground. The harvest method (Odum 1960) was followed to determine the phytomass and net primary production. The net primary productivity of different components of crops and weeds was calculated on dry weight basis and expressed in $\mathrm{g}$ $\mathrm{m}^{-2}$ day $^{-1}$ (Singh 2012) used in statistical correlation. 


\section{RESULTS AND DISCUSSION}

Chlorophyll concentration: The concentration of chlorophyll $(a+b)$ per unit dry weight of component plant material for crops and dominant weeds ( $C$. dactylon) had shown almost similar trend but varied slightly for 'other weeds' with the advance of age. The values of chlorophyll $(a+b)$ concentration per unit dry weight of leaf phytomass had similar increasing trend up to 90 days for mixed crop (wheat and mustard) and above ground parts of dominant weed ( $C$. dactylon).

The peak of leaf chlorophyll $(a+b)$ concentration $8.40 \mathrm{mg} \mathrm{g}^{-1}$ was obtained in mustard followed by wheat leaf, i.e. $8.10 \mathrm{mg} \mathrm{g}^{-1}$, both at the age of 90 days of crop. In contrast, the values were lower for stem and varied in wheat $0.85 \mathrm{mg} \mathrm{g}^{-1}$ at 90 days and mustard, $1.87 \mathrm{mg} \mathrm{g}^{-1}$ at 105 days with the advance of crop age. The chlorophyll concentration value of $1.47 \mathrm{mg} \mathrm{g}^{-1}$ in reproductive parts of mustard was more in the beginning in comparison to wheat ear, i.e. $1.32 \mathrm{mg} \mathrm{g}^{-1}$ at the age of 75 days crop plant (Table 1).

The chlorophyll concentration of each component of crops and dominant weed reached their peak value at the same time (75-90 days), although it fluctuated up to 90 days in 'other weeds' as 38 other weed species had different periodicity, some extremely short lived and some remained up to the end of crop maturity. Their appearance was largely attributed dormancy, germination requirement and soil moisture, which gave fluctuation in chlorophyll concentration. The most significant feature of recurrence of weed flora at intermittent interval is through staggered germination brought about dormancy phenomenon (Branchley and Warington 1933).

Chlorophyll density: In mixed crop of wheat and mustard the peak chlorophyll density for wheat was $756.69 \mathrm{mg} \mathrm{m}^{-2}$ whereas for mustard crop was $1259.08 \mathrm{mg} \mathrm{m}^{-2}$ at the age of 90 days of crop plant. For the total crop (wheat and mustard) the value was $1597.22 \mathrm{mg} \mathrm{m}^{-2}$ at the age of 90 days. Values for different components of wheat and mustard have increased up to the age of 90 days except wheat stem (174.65 $\mathrm{mg} \mathrm{m} \mathrm{m}^{-2}$ ), mustard stem $\left(1019.37 \mathrm{mg} \mathrm{m}^{-2}\right)$ and mustard reproductive parts $\left(25.59 \mathrm{mg} \mathrm{m}^{-2}\right)$ all at the age of 105 days of crop plant. The value for mixed crop and weeds taken together was $2825.85 \mathrm{mg} \mathrm{m}^{-2}$ at the age of 90 days of crop sowing (Table 2).

Table 1. Changes in chlorophyll $(\mathrm{a}+\mathrm{b})$ concentration per unit dry weight of plant material components $\left(\mathrm{mg}^{-1}\right)$ with advance of age for total crop and weeds at Gujar lake margin.

\begin{tabular}{|c|c|c|c|c|c|c|c|c|c|}
\hline \multirow[t]{2}{*}{ Plant } & \multirow[t]{2}{*}{ Component } & \multicolumn{8}{|c|}{ Plant age (Days) } \\
\hline & & 15 & 30 & 45 & 60 & 75 & 90 & 105 & 120 \\
\hline \multicolumn{10}{|l|}{ Total Crop } \\
\hline \multirow[t]{6}{*}{ Wheat } & Leaf & 6.73 & 6.43 & 7.41 & 7.53 & 7.85 & 8.10 & 7.25 & 4.93 \\
\hline & & \pm 0.15 & \pm 0.17 & \pm 0.10 & \pm 0.14 & \pm 0.43 & \pm 1.41 & \pm 0.52 & \pm 0.21 \\
\hline & Stem & 0.09 & 0.12 & 0.29 & 0.32 & 0.40 & 0.85 & 0.55 & 0.17 \\
\hline & & \pm 0.01 & \pm 0.004 & \pm 0.05 & \pm 0.03 & \pm 0.06 & \pm 0.09 & \pm 0.10 & \pm 0.05 \\
\hline & Ear & - & - & - & 0.97 & 1.32 & 0.89 & 0.73 & 0.24 \\
\hline & & & & & \pm 0.03 & \pm 0.15 & \pm 0.05 & \pm 0.03 & \pm 0.04 \\
\hline \multirow[t]{6}{*}{ Mustard } & Leaf & 5.37 & 6.69 & 6.58 & 7.45 & 8.25 & 8.40 & 2.40 & - \\
\hline & & \pm 0.13 & \pm 0.37 & \pm 0.67 & \pm 0.30 & \pm 0.72 & \pm 1.32 & \pm 0.09 & \\
\hline & Stem & 0.34 & 0.61 & 0.75 & 0.79 & 1.29 & 1.53 & 1.87 & 0.69 \\
\hline & & \pm 0.03 & \pm 0.05 & \pm 0.06 & \pm 0.03 & \pm 0.27 & \pm 0.49 & \pm 0.21 & \pm 0.09 \\
\hline & Reproductive part & - & - & - & - & 1.47 & 1.33 & 0.83 & 0.20 \\
\hline & & & & & & \pm 0.52 & \pm 0.34 & \pm 0.03 & \pm 0.04 \\
\hline \multicolumn{10}{|l|}{ Weeds } \\
\hline \multirow{4}{*}{$\begin{array}{l}\text { Dominant weed } \\
\text { (C. dactylon) } \\
\text { Other weeds }\end{array}$} & Above ground parts & 3.65 & 4.21 & 5.03 & 6.17 & 6.43 & 6.25 & 2.32 & 1.08 \\
\hline & & \pm 0.08 & \pm 0.31 & \pm 0.09 & \pm 0.23 & \pm 0.19 & \pm 0.24 & \pm 0.17 & \pm 0.21 \\
\hline & Above ground parts & 2.83 & 6.32 & 5.45 & 4.26 & 5.04 & 4.93 & 2.37 & 1.40 \\
\hline & & \pm 0.34 & \pm 0.21 & \pm 0.08 & \pm 0.41 & \pm 0.34 & \pm 0.83 & \pm 0.69 & \pm 0.23 \\
\hline
\end{tabular}


Table 2. Changes in chlorophyll $(\mathrm{a}+\mathrm{b})$ density per unit area of ground $\left(\mathrm{mg} \mathrm{m}^{-2}\right)$ in different components as well as total crop and weeds with advance of crop age at Gujar lake margin.

\begin{tabular}{|c|c|c|c|c|c|c|c|c|c|}
\hline \multirow[t]{2}{*}{ Plant } & \multirow[t]{2}{*}{ Components } & \multicolumn{8}{|c|}{ Plant age (Days) } \\
\hline & & 15 & 30 & 45 & 60 & 75 & 90 & 105 & 120 \\
\hline \multicolumn{10}{|l|}{ Total Crop } \\
\hline \multirow[t]{3}{*}{ Wheat } & Leaf & 48.52 & 111.59 & 219.61 & 490.05 & 553.66 & 511.68 & 273.44 & 158.65 \\
\hline & Stem & 0.07 & 0.48 & 3.91 & 13.67 & 47.90 & 167.47 & 174.65 & 66.76 \\
\hline & Ear & - & - & - & 1.75 & 43.67 & 77.54 & 75.11 & 30.42 \\
\hline \multicolumn{10}{|l|}{ Mustard } \\
\hline & Leaf & 32.22 & 86.50 & 244.18 & 487.30 & 750.91 & 698.96 & 161.11 & - \\
\hline & Stem & 8.87 & 3.30 & 11.32 & 33.26 & 197.99 & 548.38 & 1019.37 & 376.12 \\
\hline & Reproductive parts & - & - & - & - & 3.09 & 11.74 & 23.59 & 9.42 \\
\hline \multicolumn{10}{|l|}{ Weeds } \\
\hline $\begin{array}{l}\text { Dominant } \\
\text { (C. dactylon) }\end{array}$ & Above ground parts & 9.93 & 25.81 & 102.21 & 266.79 & 433.51 & 610.81 & 311.83 & 199.31 \\
\hline Other weeds & Above ground parts & 5.46 & 40.38 & 59.41 & 66.82 & 139.76 & 199.27 & 123.52 & 47.99 \\
\hline \multicolumn{2}{|c|}{ Total for Wheat } & 48.59 & 112.07 & 223.52 & 505.47 & 645.23 & 756.69 & 523.20 & 255.83 \\
\hline \multicolumn{2}{|c|}{ Total for Mustard } & 41.09 & 89.80 & 255.50 & 520.56 & 951.99 & 1259.08 & 1204.07 & 385.54 \\
\hline \multicolumn{2}{|c|}{ Total for Crops } & 89.68 & 201.87 & 479.02 & 1026.03 & 1597.22 & 2015.77 & 1727.27 & 641.37 \\
\hline \multicolumn{2}{|c|}{ Total for Weeds } & 15.39 & 66.19 & 161.62 & 333.61 & 573.27 & 810.08 & 435.35 & 247.30 \\
\hline \multicolumn{2}{|c|}{ Total for crops and weeds } & 105.07 & 268.06 & 640.64 & 1359.64 & 2170.49 & 2825.85 & 2162.62 & 888.67 \\
\hline
\end{tabular}

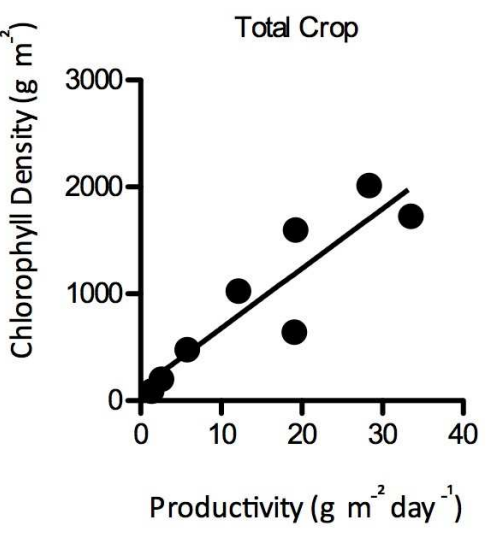

(a)

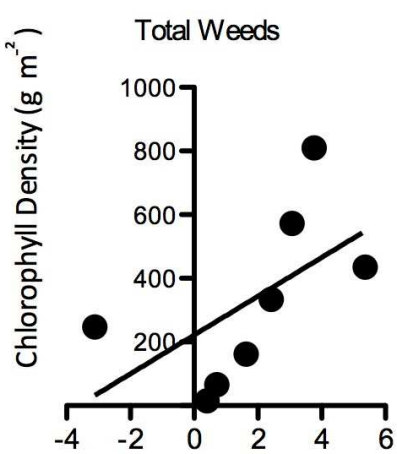

Productivity $\left(\mathrm{g} \mathrm{m}^{-2}\right.$ day $\left.^{-1}\right)$

Fig. 1. (a) Relationship between productivity $\left(\mathrm{g} \mathrm{m}^{-2} \mathrm{day}^{-1}\right)$ as dependent variable, (b) chlorophyll density $\left(\mathrm{g} \mathrm{m}^{-2}\right)$ as independent variable at study site during winter crop period.

Maximun chlorophyll density per unit area of ground $\left(\mathrm{g} \mathrm{m}^{-2}\right)$ of various vegetation types of India are as follows: Berhampur Aristida grassland 1.2 (Misra and Misra 1981), Ratlam Sehima grassland 0.7 (Billore and Mall 1976), Rajasthan desert 0.8 1.5 (Kumar and Joshi 1972), Gomati riparian agroecosystem at Jaunpur 1.99 (Ambasht et al. 1983) and $2.83 \mathrm{mg} \mathrm{m}^{-2}$ (present study).
Statistical analysis: Correlation of plant chlorophyll density $\left(\mathrm{g} \mathrm{m}^{-2}\right)$ as independent variable and productivity $\left(\mathrm{g} \mathrm{m}^{-2} \mathrm{day}^{-1}\right)$ as dependent variable has been depicted in Fig. 1 ( $a$ and b). It is clear that the chlorophyll density for total crop and total weeds vary significantly showing contrast in the productivity of the total crop and weeds, as chlorophyll concentration gives direct relationship 
with the rate of production. There was highly significant positive correlation $(r=0.903, p=$ 0.002) between chlorophyll content and productivity of total crop (Fig. 1a). Though positive correlation was also obtained for total weeds between chlorophyll density and productivity but it was insignificant $(\mathrm{r}=0.580, \mathrm{p}=$ 0.131) (Fig. 1b) which might be due to their staggered germination, short life span and more biotic pressure on some of the weeds.

The rainy season submergence and exposure also increase the fertility status on the lake margin. Therefore, the lake margins, which are left as neglected wasteland if used for winter crop cultivation, can be highly productive due to more chlorophyll and nutrient contents. There are more than dozen 'tals' in District Jaunpur among them 'Gujar tal' is the biggest one, i.e., locally known by people about 200 ha (Ambasht 2008). If intensive crop cultivation is done at lakes margin especially for winter crop it may add to the GDP (Gross Domestic Production) of the nation.

\section{ACKNOWLEDGEMENTS}

Authors are thankful to the Principal, T.D. College Jaunpur for providing laboratory facilities during the study period and Dr. N.P. Singh (Retired Reader, Department of Chemistry) for his fruitful discussion.

\section{REFERENCES}

Ambasht, R.S. 2008. Wetland ecology, an overview. Proc. National Acad. Science India, 78:3-12.

Ambasht, R.S., M.P. Singh and E. Sharma. 1983. Changes with plant age in fractionated phytomass, productivity and chlorophyll density of crops and weeds on a riparian agroecosystem. Proceedings, Ninth Conference of Asian Pacific Weed Science Society, Manila (Philippines), pp. 491-501.
Billore, S.K. and L.P. Mall. 1976. Seasonal variation in chlorophyll content of a grassland community. Tropical Ecology 17:39-44.

Brenchley, W.E. and K. Warington. 1933. The weed seed population of aerable soil: II. Influence of crop, soil and methods of cultivation upon the relative abundance of viable seeds. Journal of Ecology 21:103-127.

Wu, C., N. Zheng, T. Quan and H. Wenjiang. 2008. Estimating chlorophyll content from hyperspectral vegetation indices: Modeling and validation. Agricultural and Forest Meteorology 148:1230-1241.

Gitelson, A.A., A. Vina, S.B. Verma, D.C. Rundquist, T.J. Arkebauer, G. Keydan, B. Leavitt, V. Ciganda, G.G. Burba and A.E. Suyker. 2006. Relationship between gross primary production and chlorophyll content in crops: Implications for the synoptic monitoring of vegetation productivity. Journal of Geophysical Research 11:1-13.

Kumar, A. and M.C. Joshi. 1972. The effects of grazing on the structure and productivity of the vegetation near Pilani, Rajasthan, India. Journal of Ecology 60:665-674.

Maclachlan, C. and S. Zalik. 1963. Plastid structure, chlorophyll concentration and free amino acid composition of a chlorophyll mutant of Barley. Canadian Journal of Botany 41:1053-1062.

Milner, C. and R.E. Hughes. 1968. Methods for Measurement of the Primary Production of Grasslands. Blackwell Scientific Publications, Oxford.

Misra, C.M. and L.P. Mall. 1975. Photosynthetic structure and standing biomass of a grassland community. Tropical Ecology 16:76-80. 
Misra, M.K. and B.N. Misra. 1981. Seasonal changes in leaf area index and chlorophyll in an Indian Grassland. Journal of Ecology 69:797-805.

Newbould, P.J. 1967. Methods for Estimating the Primary Production of Forests. Blackwell Scientific Publication, Oxford.

Odum, E.P. 1960. Organic production and turnover in cold field succession. Ecol. 14:34-49.
Odum, E.P. 1971. Fundamentals of Ecology, $3^{\text {rd }}$ Edn. W.B. Saunders and Co. Philadelphia, USA.

Singh, M. 2012. Diversity, Productivity and Economic Uses of Gujar Lake-land Transition Zone Vegetation. Ph.D. Thesis, V.B.S Purvanchal University, Jaunpur, India. 